Article

\title{
Mean Wind Speed Comparison and Wind Farm Energy Prediction at Chang-Hua Offshore (Taiwan)
}

\author{
Meharkumar Barapati ${ }^{1}$, Jiun-Jih Miau 1,* and Pei-Chi Chang ${ }^{2 *}$ \\ ${ }^{1}$ Department of Aeronautics and Astronautics, National Cheng Kung University, 1 University Road, Tainan \\ 701, Taiwan; E-Mail: meharkumar.aero@gmail.com (M.B.) \\ ${ }^{2}$ Tainan Hydraulics Laboratory, National Cheng Kung University, 500, Sec.3, Anming Rd., Tainan 709, \\ Taiwan \\ * Correspondence: jimiau@mail.ncku.edu.tw (J.J.M.); Tel.: +886-6-275-7575 (ext. 63688). \\ pamchang@mail.ncku.edu.tw (P.C.C.); Tel.: +886-6-237-1938 (ext. 192)
}

\begin{abstract}
Taiwan developing offshore wind power to promote green energy and self-electricity production. In this study, a Light Detection and Ranging (Lidar) was set up at Chang-Hua development zone one on the sea and $10 \mathrm{~km}$ away from the seashore. At Lidar location, WRF $3.33 \mathrm{~km}$ $\& 2 \mathrm{~km}$ grid lengths) model and WAsP were used to simulate the wind speed at various elevations. Three days mean wind speed of simulated results were compared with Lidar data. From the four wind data sets, developed five different comparisons to find an error\% and R-Squared values. Comparison between WAsP and Floating Lidar was shown good consistency. Lukang meteorological station 10 years wind observations at $5 \mathrm{~m}$ height were used for wind farm energy predictions. The yearly variation of energy predictions of traditional and TGC wind farm layouts are compared under purely neutral and stable condition. The one-year cycle average surface heat flux over the Taiwan Strait is negative $\left(-72.5\left(\mathrm{~W} / \mathrm{m}^{2}\right)\right.$ and $\left.157.13 \mathrm{STD}\right)$, which represents stable condition. At stable condition TGC $(92.39 \%)$ and $60^{\circ}(92.44 \%)$, wind farms were shown higher efficiency. The Fuhai met mast wind data was used to estimate roughness length and power law exponent. The average roughness lengths are very small and unstable atmosphere.
\end{abstract}

Keywords: wind; wind farm; offshore; energy; lidar

\section{Introduction:}

Taiwan is an island in the world, which is rapidly developing. For the developing country, self-electricity production is also plays a major role. The usage of natural resources is increased all over the world and leads to global warming. After few years every country has to depend on the renewable energies. Already few countries like Germany, UK, and Denmark are advanced in renewable energy research and especially in wind power. Taiwan also has the potential to develop the wind energy in offshore and onshore, because of northeast and southwest monsoons. Especially during the northeast monsoon (winter), offshore winds are very high and stable over the west coastal areas of Taiwan.

Taiwan government already focused on renewable energies and expecting wind power contribution $5.3 \%$ of $15.1 \%$ by 2025 . The wind energy played a significant role in the renewable energies and developed few onshore wind farms successfully. End of the year 2012 installed more than $564 \mathrm{MW}$ wind power. Taiwan west coastal areas are very rich in wind energy resources, and offshore wind energy is still in undeveloped condition. Taiwan government expecting 1000 wind turbines by 2030 and installation would be more than 4200 MW [1,2]. 
As per the International Electrotechnical Commission (IEC) standard, at least one-year marine meteorological wind data is needed to understand the site's wind energy potential [3]. Due to underdevelopment of offshore wind data resources, the significant contribution of wind data is from central weather bureau and it is available below $10 \mathrm{~m}$ height [4]. It is very costly to install the marine meteorological mast on the sea. For installation, it will take the time to analyze the atmospheric conditions at the interesting site. At Chang-Hua sea area the waves are heavily influenced by the wind. From April to September $80 \%$ of the time, the significant wave height will be below one meter [5].

The software WAsP is very popular engineering tool for the wind energy resources assessment. Chang et al. [4], were done three days mean wind speed comparison between Lidar (located on land) and WAsP simulated results (Chiku buoy located on sea and wind data observations are recorded at $3 \mathrm{~m}$ height). The same methodology used to compare the Lidar (located on sea shore) and WAsP simulated results (Waipu tidal station located on the sea shore and wind data observations recorded at $3 \mathrm{~m}$ height). WAsP was used to estimate the mesoscale resolution area's wind energy resources at west coastal areas of Taiwan [4].

Weather Research and Forecasting (WRF) model is a numerical model used for the atmospheric research. Krogsæter and Reuder [6], (WRF) model was simulated at 3 Nested domain with five type of planetary boundary layer schemes at $100 \mathrm{~m}$ height for the wind energy application throughout the year 2005 and analyzed the average wind speed and wind shear were compared with FINO1 wind data. Low-level jet (LLJ) was examined by WRF model of Yonsei University (YSU) and Mellor-Yamada-Janjic (MJY) scheme with Doppler radar at West Texas and southern Kansas [7]. Shimada and Ohsawa were used WRF model results to compare with in-situ measurement on the sea at Shirahama research platform Japan [8].

The wind farm layout is a challenge for the wind farm developers to achieve high efficiency and less wake loss. The spacing between two turbines will play a significant role in a wind farm layout to produce less wake effect to the neighbor wind turbines. As space increases between the wind turbines, the area also increases which leads to invest more money for cables in grid connections in a wind farm. So that wind farm developers optimize the wind farm layout to decreases wake loss. Both the offshore and onshore wind farms are having its advantages and disadvantages. An offshore wind farm has greater benefits than the onshore wind farm. No health hazards like visual impact and noise. A large area is available and can construct a big project. Available of very high wind speed, so the energy production also will be great. Fewer fatigue loads and high power generation because of less turbulence [9]. The traditional wind farm layout will design in a way with respective to prevailing wind direction of the site and a maximum number of wind turbines exposed to prevailing wind direction [10]. The cross wind spacing of the wind turbines should be greater than the downwind spacing. If a site have higher wind speed in a particular direction than the wind turbines can be closely arranged. The cross wind spacing and downwind spacing of the wind turbines can give $3-4 \mathrm{~m} \& 6-10 \mathrm{~m}$ diameter of the rotor blade [11]. The cross wind space can be provided as one rotor diameter also but the problem is prevailing wind direction will not be same thought out the year [10]. From a recent publication [12] irregular wind farm layout can produce high energy production than expected. For the wind farm energy predictions, consideration of atmospheric 
stability is also important. The wake decay constant can assume lower and higher values at stable \& unstable conditions. At stable condition there will be no presence turbulent eddies in the atmosphere, so the wake expansion behind the wind turbine will take longer distance. At unstable condition, due to the presence of turbulent eddies in the air will help the wind flow to regain its velocity from the wake expansion behind the wind turbine.

Gaumond et al. [13] are mentioned for small and large offshore wind farms the wake decay constant can take as 0.4 and 0.05 . The WAsP wake model was used to find the efficiency of the NYSTED offshore wind farm belonged to the Denmark and located in Baltic sea, which is approximately $11 \mathrm{~km}$ from south of the Denmark island of Lolland. The wake decay 0.03 was shown good consistency with the observed values [14]. Large offshore wind farm HORNS REV 1 located in the North Sea approximately $14 \mathrm{~km}$ away from the west coast of Denmark, and it belongs to Denmark. This park was calibrated the wake losses and park efficiency with calculated vs. observed values given good promising results from Jensen wake modeling under the different atmospheric condition, shown that wake decay constant of $0.025,0.04,0.06$ are stable, neutral and unstable atmospheric conditions [15]. Hasager et al. [16] were examined the wind flow around the offshore wind farms in the North Sea with the help of satellite SAR data. HORNS REV 1 offshore wind farm wake modeling was done with the WRF data and considered three types of wake decay constants $0.03,0.04 \& 0.5$. The higher and lower values used in the stable and unstable conditions. From the reference [16] a subpart was presented in a conference paper [17] given wake decay constant 0.03 was taken for the wind farms in the North Sea to know the shadow effect from the neighboring wind farms.

Bergeron, N. et al. [18] estimated the roughness lengths and friction velocity from the wind profile. The roughness length is also a significant parameter for the prediction of vertical wind profile. The roughness length is not constant always, and it depends on the wave field. The wind speed also influenced by the waves. Lange, B et al. [19] clearly explained the four different methods to estimate the sea surface roughness length.

- The assumption of roughness length for many applications will be taken as $0.2 \mathrm{~mm}$ and, WAsP (Wind Atlas Analysis and Application Program) is an example.

- Charnock relation is a method to estimate the roughness length with the help of wave field encountered by the friction velocity. This method works well for the open ocean.

$$
\mathrm{Z}_{0}=\mathrm{Zch}\left(\mathrm{u}^{* 2} / \mathrm{g}\right)
$$

Where $\mathrm{g}=$ acceleration due to gravity and, $\mathrm{zch}_{\mathrm{ch}}$ is the empirical Charnock parameter. The $\mathrm{z}_{\mathrm{ch}}=0.0185$ will take in standard practice.

- Wave age model (Zch)

The Charnock relation is a site specific for example all the coastal areas will not have same physical properties like fetch over the wave field.

$$
\mathrm{Zch}=\mathrm{A}\left(\mathrm{c}_{\mathrm{p}} / \mathrm{u}^{*}\right)^{\mathrm{B}}
$$


Where $c_{p} / u^{*}$ is the wave age, $c_{p}$ velocity of the peak wave component and $u^{*}$ friction velocity. (1.89) and B (-1.59) are the empirical constants.

- Fetch model is the empirical relation between the dimensionless peak frequency and the dimensionless fetch

$$
\left(u^{*} / g\right) \omega_{p}=C\left[\left(g / u^{* 2}\right) x\right]^{D}
$$

Where $\omega_{\mathrm{p}}=$ peak wave frequency, $\mathrm{x}$ fetch in meters. $\mathrm{C}=3.08$ and $\mathrm{D}=-0.27$ are proportional coefficients.

\section{Research Methodology:}

\subsection{Wind Data Resources at Chang-Hua.}

In this study, the six different locations wind data are used, and locations are shown in Figure 1. Floating Lidar is located on Sea and about $10 \mathrm{~km}$ away from the seashore. The wind speed observation heights are $55 \mathrm{~m}, 70 \mathrm{~m}, 90 \mathrm{~m}, 110 \mathrm{~m}, 150 \mathrm{~m}$ and $200 \mathrm{~m}$ and data is recorded at 10 minutes time interval. The Lidar specifications are available in [4].

Mailiao tidal station is located on the seashore and about $26 \mathrm{~km}$ away from the Lidar location. The wind speed observational height is at $5 \mathrm{~m}$, and data recorded at one hour time interval.

At Lidar location wind data is simulated by using Weather Research and Forecasting (WRF) model version 3.7.1. The default model Yonsei University (YSU) planetary boundary layer (PBL) scheme is used. The second domain simulated with two different grid lengths $(3.33 \mathrm{~km}$ and $2 \mathrm{~km})$. The wind speed simulation heights are same as Lidar observations and data recorded at a one hour time interval. All the above wind data's are available from 27 September to 25 November / 2014.

Lukang meteorological station (4G21) located at the sea shore. The long term ten years wind data is available from 2001 to 2010. The wind data observational height is at $5 \mathrm{~m}$ and data recorded at a one-hour interval.

Fuhai met mast is located at the Chang-Hua development zone one and about $9 \mathrm{~km}$ away from the seashore. The wind data observation heights are $10 \mathrm{~m}, 30 \mathrm{~m}, 50 \mathrm{~m}, 86 \mathrm{~m}$ and recorded at 10 minutes interval. The wind data is available from 10 October to 5 November / 2015. 


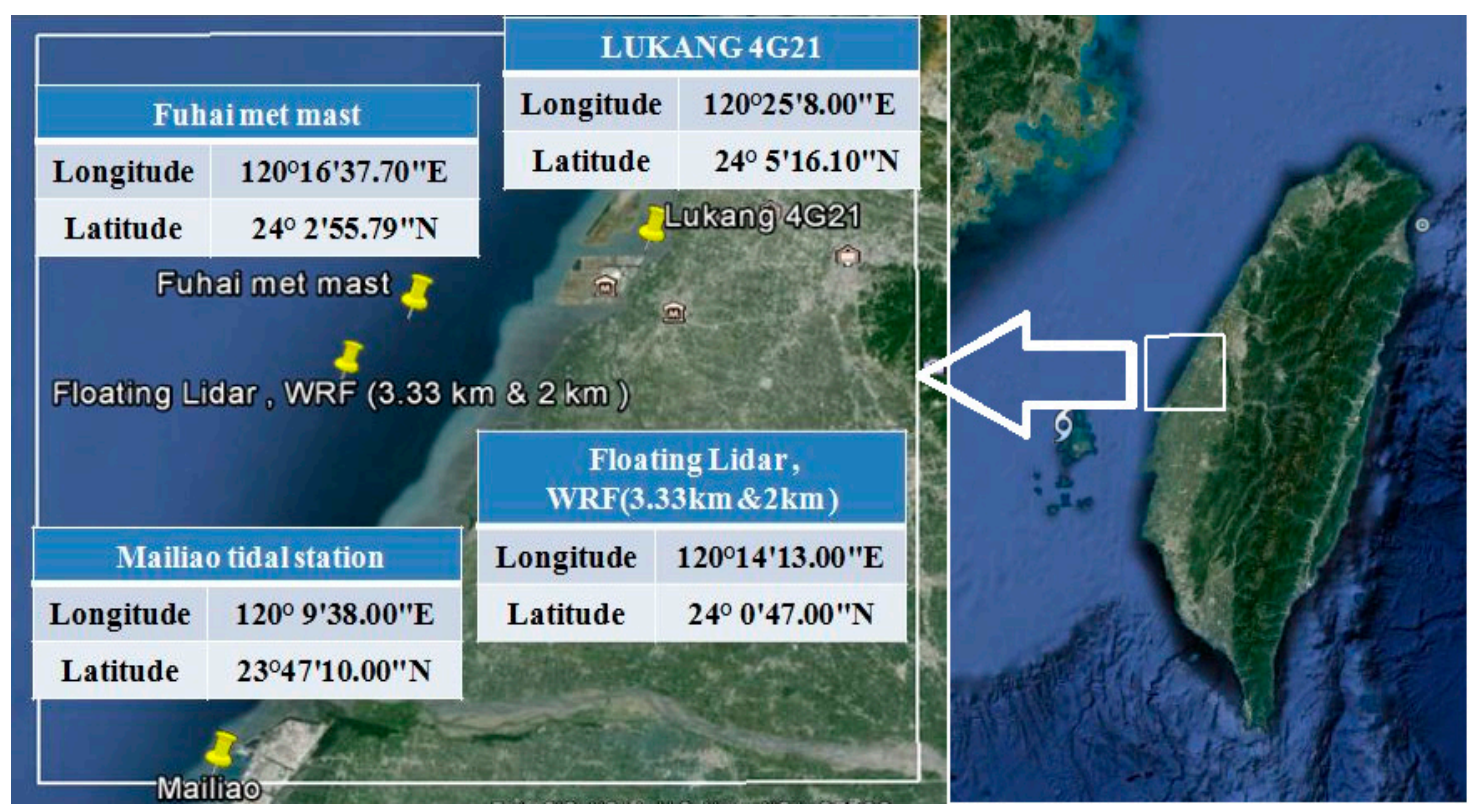

Figure 1. Wind data resources at Chang-Hua area

2.2. WAsP (Wind Atlas Analysis and Application Program).

It is an Engineering tool; used to predict the wind resources, wind climate, wind farm energy productions, etc. It was introduced in the year of 1987 by the wind energy and atmospheric physics department at Risø National Laboratory. It's a PC-program and user-friendly. The Chang-Hua area contour map and surface roughness were shown in reference [4].

At Fuhai met mast location, three wind farm layouts are designed leading towards $0^{\circ}, 30^{\circ}$ and $60^{\circ}$ concerning North, in a clockwise direction as shown in Figure 2 . The wind farms spacing are took from TGC wind farm's middle located wind turbines. As per the TGC Company terms and condition, the wind farm details are not supposed to publish. The TGC wind farm layout is available on the company website [5].

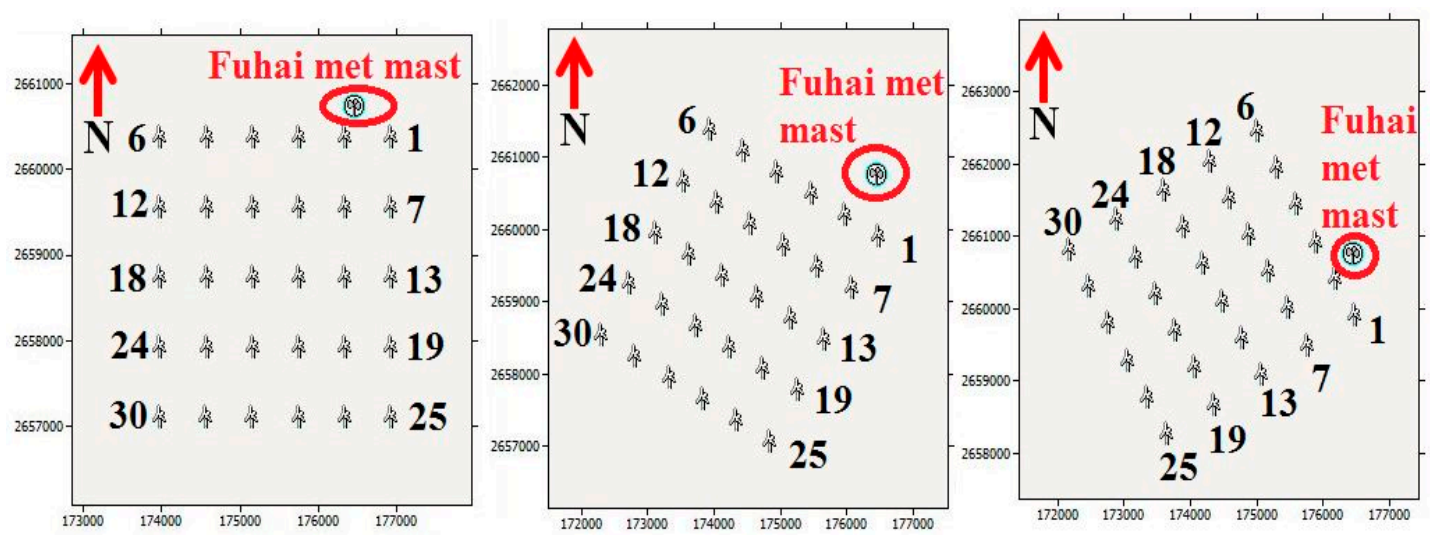

Figure 2. Wind farms leading towards $0^{\circ}, 30^{\circ}, 60^{\circ}$ degrees concerning north, in a clockwise direction and wind turbines site identity number at Chang-Hua area.

2.3. Estimation of Roughness length from vertical wind profiles. 
Assuming log wind profile equation at near neutral stable condition and shown in Equation (4).

$\mathrm{U}(\mathrm{z})=\left(\mathrm{u}^{*} / \kappa\right) \ln (\mathrm{z})-\left(\mathrm{u}^{*} / \kappa\right) \ln (\mathrm{z} 0)$

The Equation (4) is assuming as a line Equation (5),

$y=b x+a$

Hence from Equation (4) and Equation (5)

$\mathrm{y}=\mathrm{U}(\mathrm{z}) ; \quad \mathrm{U}(\mathrm{z})=$ wind speed

$\mathrm{b}=\left(\mathrm{u}^{*} / \mathrm{k}\right)$

$\mathrm{u}^{*}=$ friction velocity, $\mathrm{k}=$ von Karman Constant $(0.4)$

$\mathrm{x}=\ln (\mathrm{z})$; $\mathrm{z}=$ wind speed observed different heights

$\mathrm{a}=-\left(\mathrm{u}^{*} / \mathrm{k}\right) \ln (\mathrm{z} 0) ; \quad \mathrm{z}_{0}=$ Surface roughness length $(\mathrm{m})$

Fuhai met wind mast data is used to estimate the roughness length. The wind speed observation heights are $10 \mathrm{~m}, 30 \mathrm{~m}, 50 \mathrm{~m}$, and $86 \mathrm{~m}$. The wind data should check carefully, as height increases with wind speed also increase and it is recommended to take mean values.

\section{Results and Discussion}

\subsection{Mean Wind Speed Comparison.}

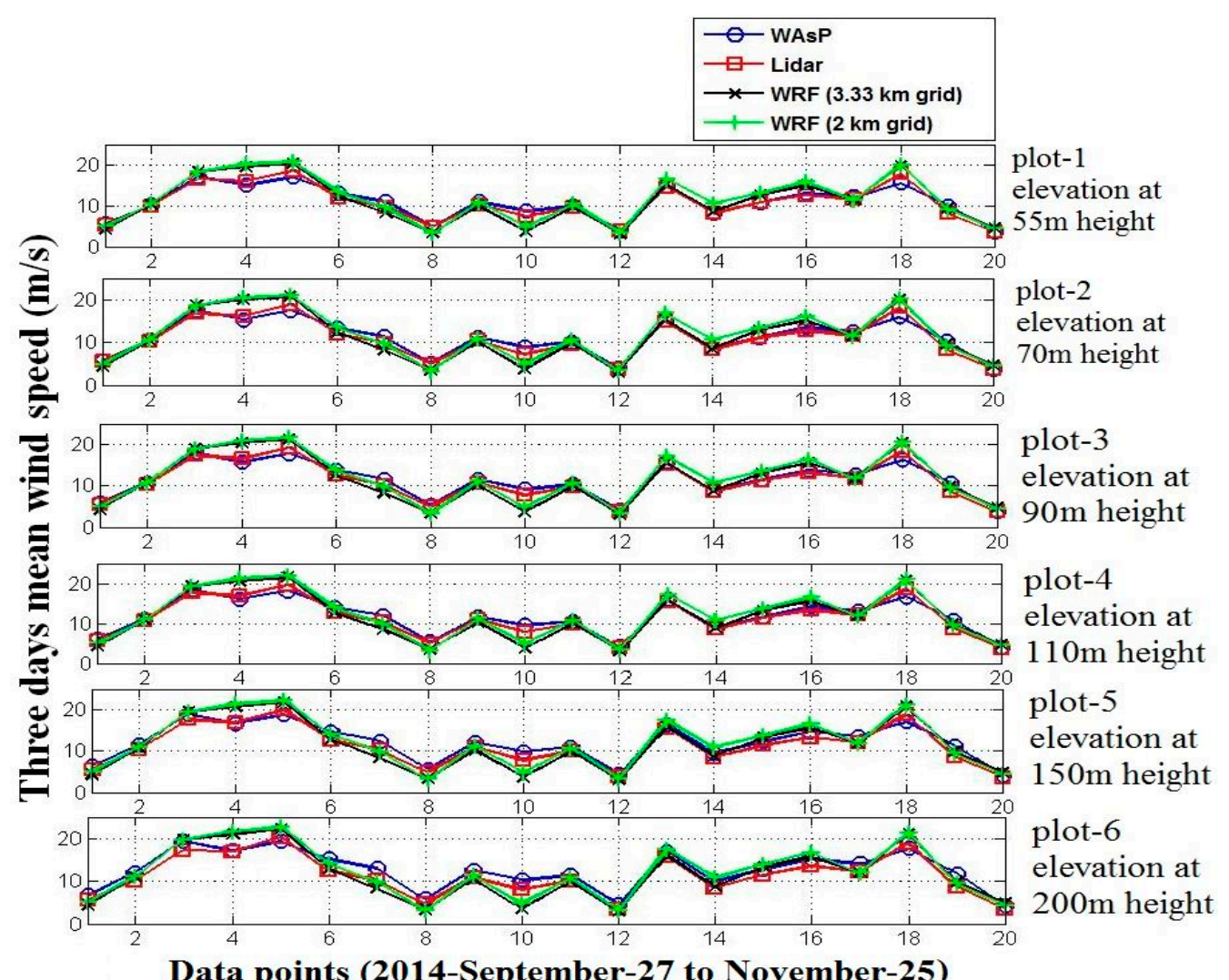

Figure 3. Twenty data points of four wind data sets comparison of three days mean wind speed. 
The four wind data sets of Lidar, Mailiao, WRF (3.33 km grid length) and WRF (2 km grid length) are available at the same period, from 27 September to 25 November / 2014. Totally 60 days and divided into 20 data points. Therefore, three days is equal to one data point. The twenty data points of $5 \mathrm{~m}$ height Mailiao wind data observations are used to simulate the mean wind speed $(\mathrm{m} / \mathrm{s})$ of various heights $55 \mathrm{~m}, 70 \mathrm{~m}, 90 \mathrm{~m}, 110 \mathrm{~m}, 150 \mathrm{~m}, 200 \mathrm{~m}$ at Lidar location. The WRF (3.33km and 2 $\mathrm{km}$ grid lengths) and Lidar wind data sets are available at same WAsP simulated heights. The four wind data sets mean wind speed $(\mathrm{m} / \mathrm{s})$ compared and shown in Figure 3. The horizontal axis is taken as time series and a vertical axis is three days mean wind speed. All the plots look similar and tough to judge which data set is accurately matched with real wind speed (Lidar). To know which data set is accurate for short time predictions, so that developed five cases of comparison and found error percentage.

Error percentage $=\{($ approximate wind speed - exact wind speed $) /($ exact wind speed $)\}$

\begin{tabular}{|c|c|c|c|}
\hline Case: 1 - & WAsP & vs. Lidar & (exact value $=$ Lidar $)$ \\
\hline Case: 2 - & WRF (3.33km grid) & vs. Lidar & (exact value $=$ Lidar $)$ \\
\hline Case: 3 - & WRF (2 km grid) & vs. Lidar & (exact value $=$ Lidar $)$ \\
\hline Case: 4 - & WRF (3.33km grid) & vs. WAsP & $($ exact value $=\mathrm{WAsP})$ \\
\hline Case: 5 - & WRF (2 km grid) & vs. WAsP & $($ exact value $=\mathrm{WAsP})$ \\
\hline
\end{tabular}

The five cases of various heights error\% of twenty data points' as shown in Figure 4. First, case one is taken for the discussion. The reason for the comparison is to estimate the software accuracy and performance. It is necessary to verify the counter terrain map, roughness lengths and met mast location for the wind energy prediction. It is very common practice to take long-term data for the predictions but from this concept analyzing the short term data's are taken to understand how far it is efficient for wind climate predictions. From the case one, it is very clear that all the data points are below $110 \mathrm{~m}$ height and the error $\%$ is less than 20, except data points $10 \& 19$. Negative error\% represents that exact wind speed is larger than the approximate wind speed.

The simulated results are depend on quality of the wind data. Here a question arises Lidar wind data has error or WAsP simulated results are an error. But the other data points are simulated well so there might be a chance of error data from Lidar. It is impossible to check past what happen on the sea. In weather website [20] showed that on 25 October 2014 (data point 10) was raining at Chang-Hua. During rain, Lidar can record wrong wind speed and it depends on the intensity of raindrop because the water drops deposited over the beam opening. From the same weather website [20] showed that on 21 November 2014 (data point 19) during the daytime wind speed very less and different wind direction, when compared with other days. The data points 6, 7, 8 located in Typhoon Vongfong (Ompong) [21] period. The Lidar observation of wind speed is lesser than WAsP simulated. WAsP simulated as per the input wind data and due to different climatic condition at both places, the error $\%$ is high at $150 \mathrm{~m}$ and $200 \mathrm{~m}$ height. Below $110 \mathrm{~m}$ height the error\% values are less than $20 \%$ and shown good consistency with other data points. From the case one, it is concluded that roughness length and terrain map are good enough for short period wind climate simulation. 
For the discussion considering two positive $(4 \& 14)$ and negative $(8 \& 10)$ data points. Data point 4 shown positive errors above $20 \%$ in all the cases, except case 1 because of Lidar mean wind speed $(\mathrm{m} / \mathrm{s}$ ) is higher than the WAsP simulated. But for the other cases, WRF (3.33 km \& $2 \mathrm{~km}$ grid lengths) wind speed is greater than the Lidar and WAsP simulated. YSU boundary layer scheme which is default model in WRF will overestimate the wind speeds at $15(\mathrm{~m} / \mathrm{s})$ [6]. The WRF $2 \mathrm{~km}$ grid overestimated than the WRF $3.33 \mathrm{~km}$ grid. Data point 14 is a special case, because Lidar, WAsP, WRF $3.33 \mathrm{~km}$ grid mean wind speeds are very close. The error $\%$ of case $1,2,4$ are less than $5 \%$, but the cases $3 \& 5$ compared with WRF $2 \mathrm{~km}$ grid, so the error rate is very high than the other cases. The difference between same height MWS (m/s) of WRF grid $3.33 \mathrm{~km}$ and $2 \mathrm{~km}$ are almost close to $2(\mathrm{~m} / \mathrm{s})$. Based on the difference the apparent wind speed overestimated but not the wind shear.

Data point 8 except case 1 remaining all the cases; the error percentages are negative and more than $28 \%$. WRF ( $3.33 \mathrm{~km} \& 2 \mathrm{~km}$ grid) underestimated wind speed and the WRF $3.33 \mathrm{~km}$ grid wind speed is higher than WRF $2 \mathrm{~km}$ grid. Data point 10 is also a special case because all the cases error percentages are more than $-15 \%$. The WRF $3.33 \mathrm{~km} \& 2 \mathrm{~km}$ grid underestimated wind speed and the WRF $2 \mathrm{~km}$ grid wind speed higher than WRF $3.33 \mathrm{~km}$, which is opposite to data point 8 .

WRF model will overestimate at wind speed $15(\mathrm{~m} / \mathrm{s})$, and poor predictions are stable conditions [6]. Comparing three days mean wind speed is also showing considerable variation from both grid lengths simulation. Totally different behavior in data point to point and both WRF grid 3.33 $\mathrm{km} \& 2 \mathrm{~km}$ simulation for the short period is not recommended. The YSU boundary layer scheme simulations are useful for the unstable condition. If there is no appropriate information about the stability MYJ scheme is suggested [6]. The MYJ scheme shown significant bias below $1000 \mathrm{~m}$ and increased towards surface layer, due to the overestimation of sea surface temperature [8].
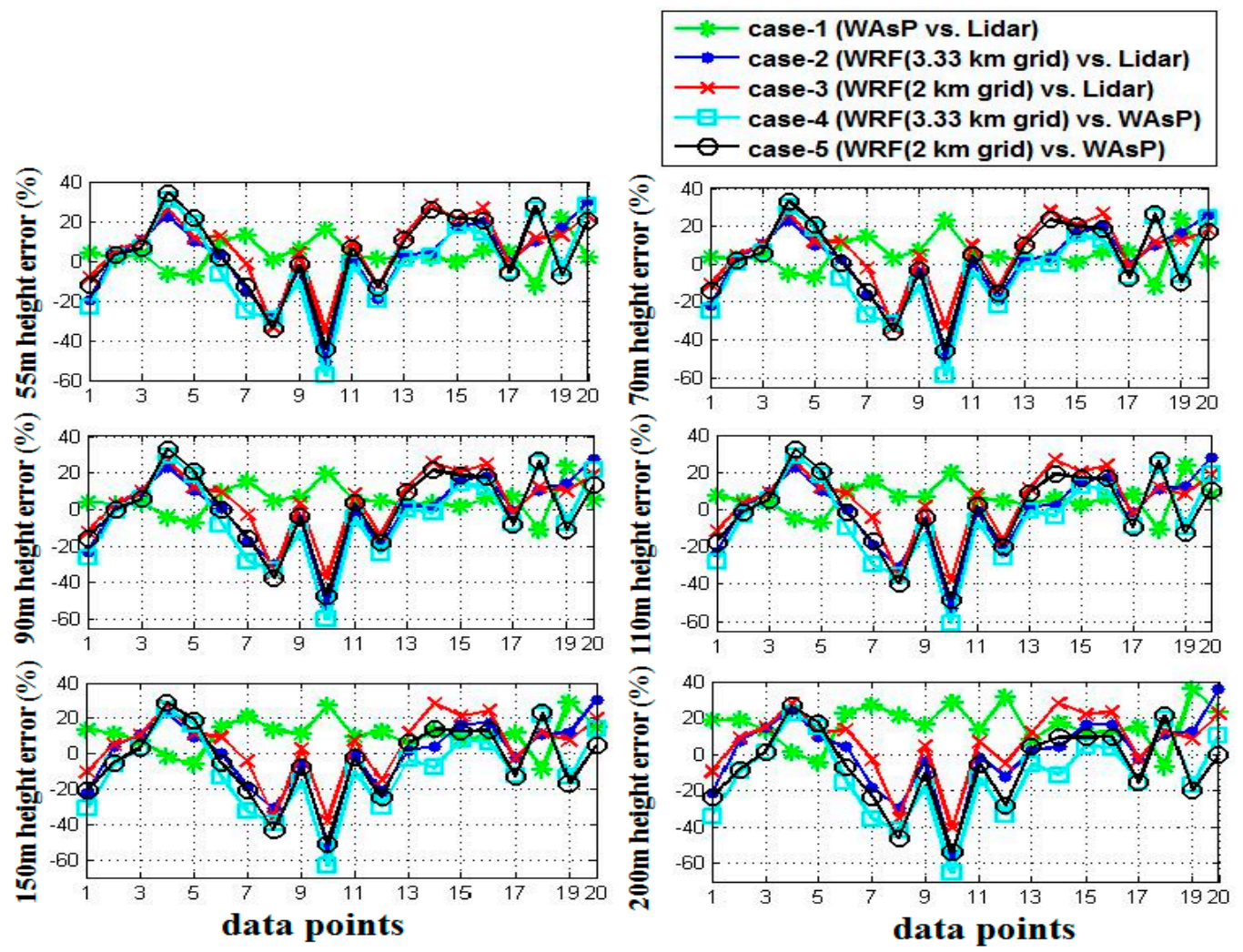

data points

data points 
Figure 4. Five cases error percentages of various elevations.

Table 1. Five cases of R-squared values.

\begin{tabular}{ccccccc}
\hline Cases & $55 \mathrm{~m}$ height & $70 \mathrm{~m}$ height & $90 \mathrm{~m}$ height & $110 \mathrm{~m}$ height & $150 \mathrm{~m}$ height & $200 \mathrm{~m}$ height \\
\hline Case-1 & 0.96 & 0.95 & 0.96 & 0.96 & 0.95 & 0.94 \\
Case-2 & 0.944 & 0.948 & 0.944 & 0.943 & 0.943 & 0.933 \\
Case-3 & 0.952 & 0.956 & 0.954 & 0.953 & 0.953 & 0.952 \\
Case-4 & 0.884 & 0.882 & 0.880 & 0.877 & 0.873 & 0.867 \\
Case-5 & 0.902 & 0.900 & 0.899 & 0.897 & 0.893 & 0.890 \\
\hline
\end{tabular}

The R-squared values of all the cases are examined and shown in Table 1, to understand how well the data is fit. For case 1 all the R-squared values are above 0.94 and 0.94 is the lowest values at $200 \mathrm{~m}$ height, which means data is not well fitted at higher altitude. The R-squared values gave good consistency and agreement with reference [4]. In reference [4] the comparisons are made the same way, but both wind data resources are located at the seashores and obtained R-squared values were above 0.93 .

From Table 2 considering long term, data is reasonable for the simulation. In case 1 error percentage increase with height increases. Below $110 \mathrm{~m}$ height error $\%$ is less than 10 . Case 3 error $\%$ showed variations at heights $90 \mathrm{~m}$ and $110 \mathrm{~m}$. Due to the lack of atmospheric stability information, it's very difficult to conclude the reasons.

Table 2. Five cases various heights average error percentage of twenty data points

\begin{tabular}{ccccccc}
\hline Cases & $\begin{array}{c}55 \mathrm{~m} \\
\text { height }\end{array}$ & $\begin{array}{c}70 \mathrm{~m} \\
\text { height }\end{array}$ & $\begin{array}{c}90 \mathrm{~m} \\
\text { height }\end{array}$ & $\begin{array}{c}110 \mathrm{~m} \\
\text { height }\end{array}$ & $\begin{array}{c}150 \mathrm{~m} \\
\text { height }\end{array}$ & $\begin{array}{c}200 \mathrm{~m} \\
\text { height }\end{array}$ \\
\hline Case-1 (\%) & 6.14 & 7.37 & 7.40 & 8.25 & 12.45 & 17.28 \\
Case-2 (\%) & 14.52 & 14.32 & 14.34 & 14.42 & 14.80 & 15.20 \\
Case-3 (\%) & 15.31 & 15.10 & 14.98 & 14.88 & 15.25 & 15.68 \\
Case-4 (\%) & 16.43 & 16.55 & 17.07 & 17.62 & 18.65 & 19.56
\end{tabular}




$\begin{array}{lllllll}\text { Case-5 }(\%) & 16.61 & 16.42 & 16.44 & 16.54 & 16.68 & 17.06\end{array}$

\subsection{At 100 m Height Yearly Variation of Probability\% and Wind Speed at Fuhai met mast Under Neutral \&} Stable Condition.

Lukang 10 years wind data is separated yearly from 2001 to 2010. To understand the variation of probability\% at Fuhai met mast, which is used to explain the wind farm energy predictions. The yearly changes of probability\% is shown in Figure 5. The dominant wind direction is from northeast especially at $30^{\circ}$. From 2001 to 2006 all the probability \% values are above $40 \%$ and from 2007 to 2010 the probability $\%$ is reduced to less than 38 , so that the ten years mean it fallen to $39.9 \%$. At the same time, probability $\%$ at $0^{\circ}$ (north) increases from 2007 to 2010, and all the values are above $18 \%$. At $60^{\circ}$ the probability $\%$ is entirely opposite to the $0^{0}$ from 2007 to 2010 . The values are decreased less than $6.4 \%$. The southwest monsoon probability\% is less than $7 \%$ in all the ten years which represent less number of prevailing winds. In WAsP change of offset heat flux value zero and negative to simulate the wind profile under neutral and stable atmospheric condition. At zero heat flux simulation will run at the purely neutral state. Average of one-year heat flux $\left(-72.5 \mathrm{~W} / \mathrm{m}^{2}\right)$ over the Taiwan Strait is used to simulate at the stable condition and shown in Table 3. The same heat flux value gave to all the years. WAsP simulated yearly variation of average wind speed $(\mathrm{m} / \mathrm{s})$ under purely neutral and stable condition at Fuhai met mast as shown in Table 4.

Table 3. Classification seasons and seasonal heat flux over Taiwan Strait Sea [1].

\begin{tabular}{cccc}
\hline Winter & Spring & Summer & Fall \\
$-220\left(\mathrm{~W} / \mathrm{m}^{2}\right)$ & $-30\left(\mathrm{~W} / \mathrm{m}^{2}\right)$ & $+130\left(\mathrm{~W} / \mathrm{m}^{2}\right)$ & $-170\left(\mathrm{~W} / \mathrm{m}^{2}\right)$ \\
\hline Nov, Dec, Jan, & Apr, May & Jun, Jul, & Sep (16-30), Oct \\
Feb, Mar & & Aug, Sep(1-15) &
\end{tabular}

Table 4. Yearly variation of average wind speed $(\mathrm{m} / \mathrm{s})$ under purely neutral and stable condition at Fuhai met mast.

\begin{tabular}{|c|c|c|c|c|c|c|c|c|c|c|c|}
\hline year & 2001 & 2002 & 2003 & 2004 & 2005 & 2006 & 2007 & 2008 & 2009 & 2010 & Mean \\
\hline $\begin{array}{c}\text { Neutral } \\
\text { condition } \\
(\mathrm{m} / \mathrm{s})\end{array}$ & 9.70 & 8.36 & 8.83 & 9.25 & 9.18 & 9.47 & 8.85 & 9.20 & 8.67 & 8.13 & 8.94 \\
\hline $\begin{array}{c}\text { Stable } \\
\text { condition } \\
(\mathrm{m} / \mathrm{s})\end{array}$ & 12.15 & 10.83 & 11.20 & 11.85 & 11.45 & 11.85 & 11.31 & 11.68 & 11.04 & 10.50 & 11.41 \\
\hline
\end{tabular}




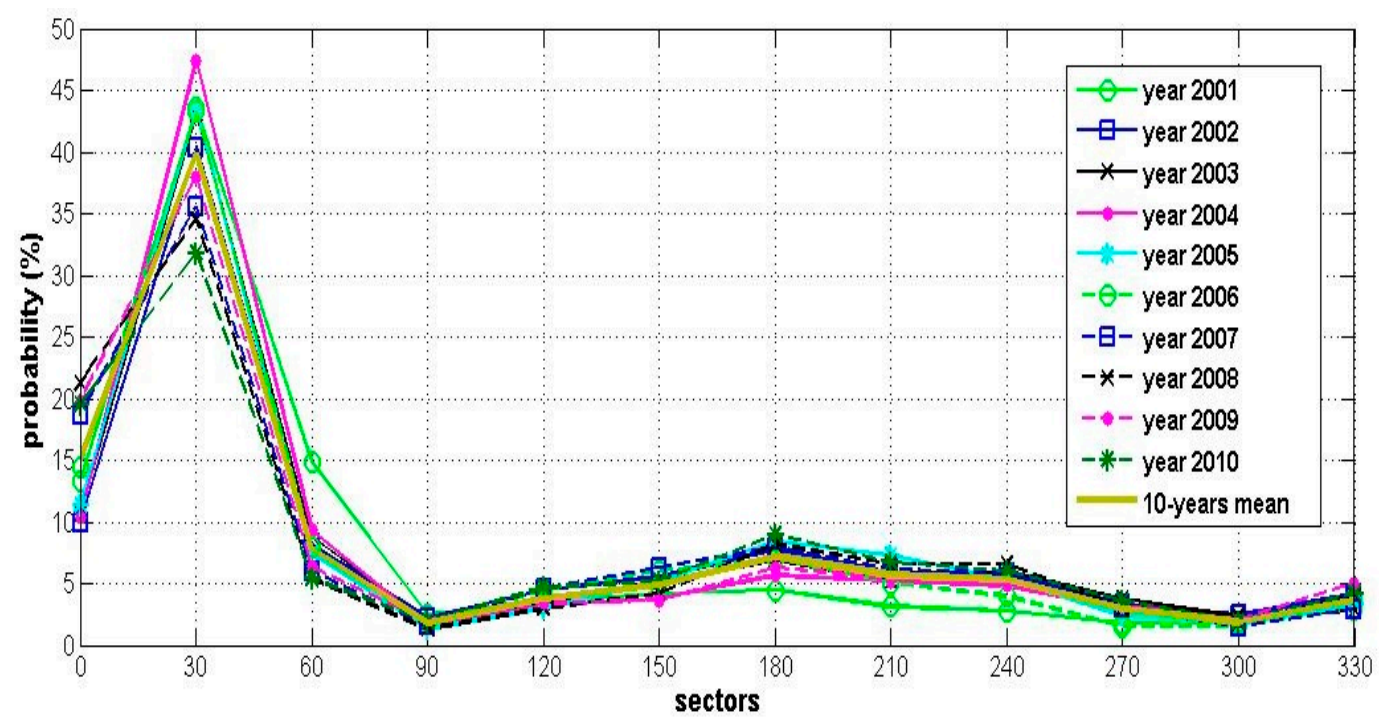

Figure 5. Lukang 10 years wind data, the yearly variation of probability\% from 2001 to 2010 at Fuhai met mast.

\subsection{Yearly Variation of Wind Farms Energy Prediction.}

Lukang 10 years wind data is used for this study. The yearly variation of wind farms $\left(0^{\circ}, 30^{\circ}\right.$, $60^{\circ}$ and TGC) energy predictions are done under purely neutral and stable condition as shown in Figure 6 . The wake decay constants are used 0.025 for stable and 0.04 for the purely neutral condition [15]. The TGC wind farm layout is available on the company website [5]. In the year 2001, southwest monsoon is weak and northeast monsoon is strong. In the north direction, probability\% from 2001 to 2005 is less and very high from 2006 to 2010. In $30^{\circ}$ direction probability\% from 2001 to 2006 is very high and very less from 2007 to 2010. In $60^{\circ}$ direction probability\% from 2001 to 2006 is higher when compared from 2007 to 2010 . The $30^{\circ}$ wind farm layout neutral (black dash-dotted line) and stable (black dotted line) condition efficiency\% curves are the same path throughout ten years. The $30^{\circ}$ wind farm layout predicted lower efficiency $\%$ among all the wind farm layouts. The $0^{0}$ wind farm layout efficiency at neutral (blue dash-dotted line) and stable (blue line dotted) condition from 2001 to 2005 is very high but from 2006 to 2010 is reducing steadily because north direction wind probability\% increased. If rising in north direction wind probability, the leading wind turbines will run with full power and rear wind turbines will experience more wake effect. Ten wind turbines (wind turbine identity numbers -1 to $7,13,19,25$ ) are predicting high efficiency than the other wind turbine. The $60^{\circ}$ wind farm layout efficiency at neutral (green dash-dotted line) and stable (green dotted line) condition from 2001 to 2005 is quite high but from 2006 to 2010 is increased steadily because north direction wind probability\% increased. The TGC wind farm layout spacing is not uniform and regularly arranged. Few wind turbines spacing is large and middle located wind turbines spacing is consistent. At the neutral condition (red dash-dotted line) the curve is followed $30^{\circ}$ wind farm layout neutral condition (black dash-dotted line,) and almost the efficiency is very close. But at the stable condition (red dotted line) TGC efficiency curve is followed the $60^{\circ}$ wind farm layout at stable (green dotted line) condition curve. TGC wind farm layout for the stable condition the efficiency is 
high and designed in a way that wind turbines will not experience more wake loss when direction probability is changed from 0 to 60 (or) 60 to 0 sectors.

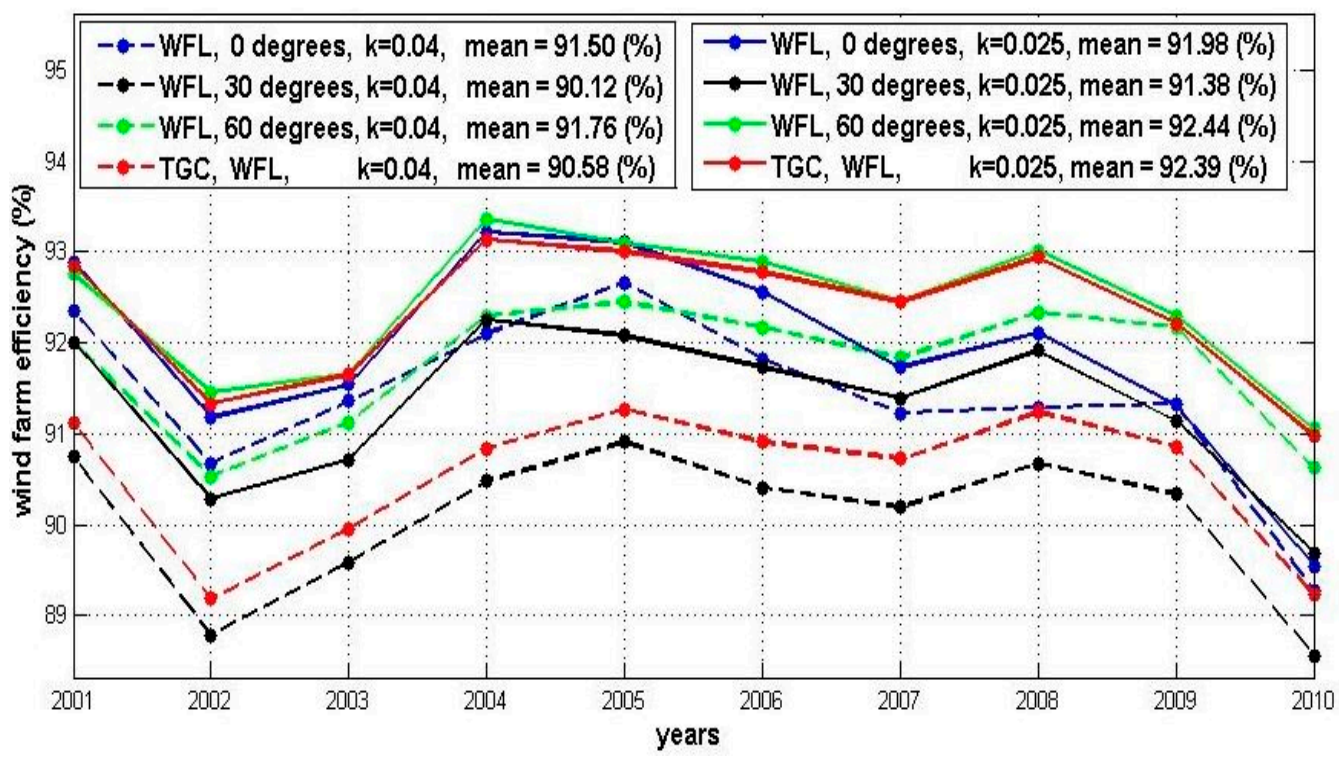

Figure 6. Comparison of yearly variation of wind farms efficiency\% at purely neutral and stable condition.

To develop a stable condition, heat flux considered for the reference [1]. Updating negative surface heat flux in WAsP generates stable atmospheric wind climate. The one year cycle of heat flux is for whole Taiwan Strait. From the literature survey, the west coastal areas of Taiwan have unique features and high winds are available in northeast monsoon when compared with southwest monsoon. The northeast monsoon begins from mid-September and the peaks winds are from October to February and have weaker till April. The wind speed of southwest monsoon is much weaker and occurs in June \& July [1]. "Typhoons" will influence southwest monsoon which most commonly occurs in the months of July, August, and September [23]. In general, the northeast monsoon and southwest monsoon transition take place in April and October [24]. Only in the summer season, the wind direction is from southwestern and other seasons are from northeast direction [22]. Throughout the year warm water currents flow from south to north [22]. In reference [1] showed a clear picture sea currents flow towards south to north in winter and summer. The sea currents will be accelerated towards the north in summer due to the southwest monsoon and slow down at northeast monsoon in winter. The sea surface pattern will be more complicated during winter than summer [22]. The surface wind speed changes with the sea surface temperature [22]. During summer in Taiwan Strait generates heat itself. The warm water comes from the Philippines Sea to the Taiwan Strait. The East China Sea surface temperature will be low compared with the South China Sea. The sea current flows at China coastal areas of Taiwan Strait is south to north in summer and north to south in winter. From the above survey points, it is clear that the Taiwan Strait's west coastal areas of the southern part will be an unstable atmospheric condition. There are very high chances of unstable atmospheric condition at the Fuhai met mast location. It very tough to conclude the atmospheric condition at Fuhai met mast without valid data because it located at the middle of Taiwan.

\subsection{Estimation Roughness length and Power law exponent ( $p$ ).}


Fuhai met mast 26 days (10 October to 5 November / 2015) wind data is available at various heights $(10 \mathrm{~m}, 30 \mathrm{~m}, 50 \mathrm{~m}$, and $86 \mathrm{~m})$. Wind data categorized as daytime (06.00am to 06.00pm), night time $(06.00 \mathrm{pm}$ to $06.00 \mathrm{am})$ and one day is 24 hours, so finally 78 data points are done and used to estimate roughness lengths as shown in Figure 7.

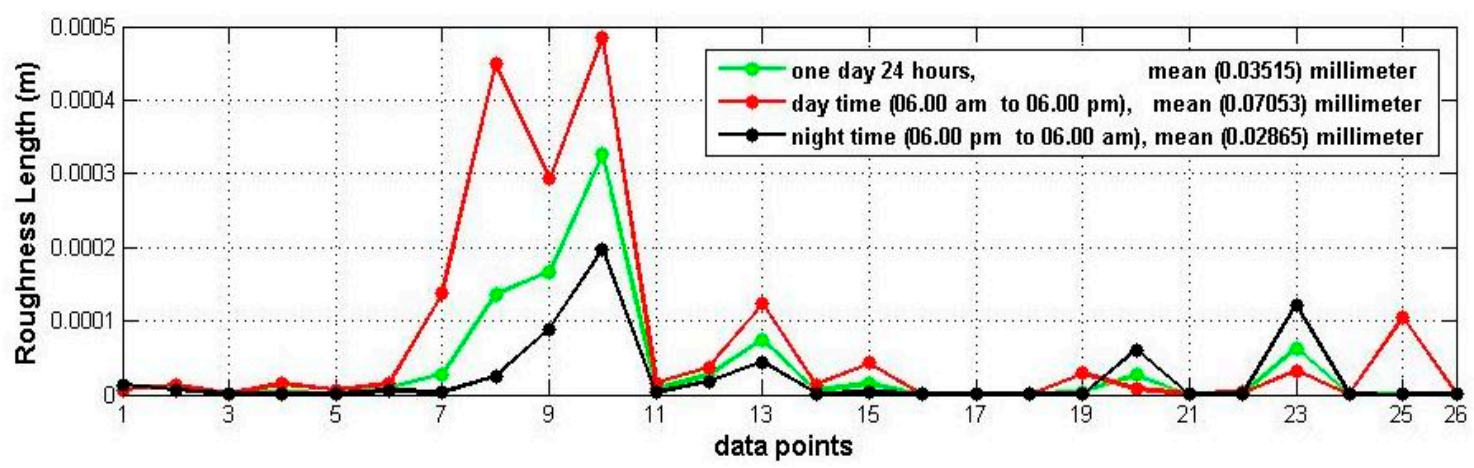

Figure 7. Roughness lengths estimation at Fuhai met mast

At Fuhai met mast the daytime wind speed is higher than the night time. In common practice, long term data is preferred for roughness lengths estimation. The average roughness length of all the data points one day, day time and night time are $0.035 \mathrm{~mm}, 0.070 \mathrm{~mm} \& 0.02 \mathrm{~mm}$. For the wind energy applications, $0.2 \mathrm{~mm}$ roughness length will be considered as a common practice. Only a few points are showing very high roughness lengths, and remaining data points are showing very less roughness lengths. It's quite surprising because west coastal areas of Taiwan Strait wave pattern will be complicated during the winter season. The surface shear stress should be high because water currents flow from south to north and strong winds received from northeast direction. Wind direction at day time and night time as shown in Figure 8.

From the Figure 8, up to data points 15, all the heights wind direction is at $30^{\circ}$ and remaining data points wind directions are randomly located. There should be uniform roughness lengths up to 15 data points but data points 8,9,10 are above the standard value. During these data points 8,9,10 periods, a tropical cyclone occurred Philippines Sea. Typhoon called Koppu [25] formed on October $12^{\text {th }}$ and dissipated on October $21^{\text {st }}$. From 16 to 26 data points wind direction is not uniform, and no data points reached roughness length $0.0002 \mathrm{~m}$. October end is the time for season transition fall to winter season [24], this might be one of the reasons, on the other hand, atmospheric stability also has tendencies to change in wind direction and can develop more turbulent eddies, Which reduces the wind speed and increases turbulence intensity. Hence there might be pressure different in both monsoon directions. Further research is needed to verify the roughness length in detail.

The power law exponent $(\mathrm{p})$ estimated from the relation $\mathrm{p}=\left(\mathrm{u}^{*} / \mathrm{k} \mathrm{u}\right)$ [26], and shown in Figure 9. Where $u_{z}$ is wind speed height and $k$ is Von Karman constant 0.4. The exponent (p) over open water bodies will be taken as 0.11 , when the atmosphere is at near neutral stable condition [27]. The temperature will increases with height at the stable condition, and temperature will decreases with height at unstable condition. Data points $8,9,10$, are close to near neutral stable condition and remaining all the points are in unstable condition. During night time at Fuhai met mast atmosphere 
is in unstable condition. Up to data points 15 there is no considerable variation but after 15 data point few points are shown day time is unstable condition.

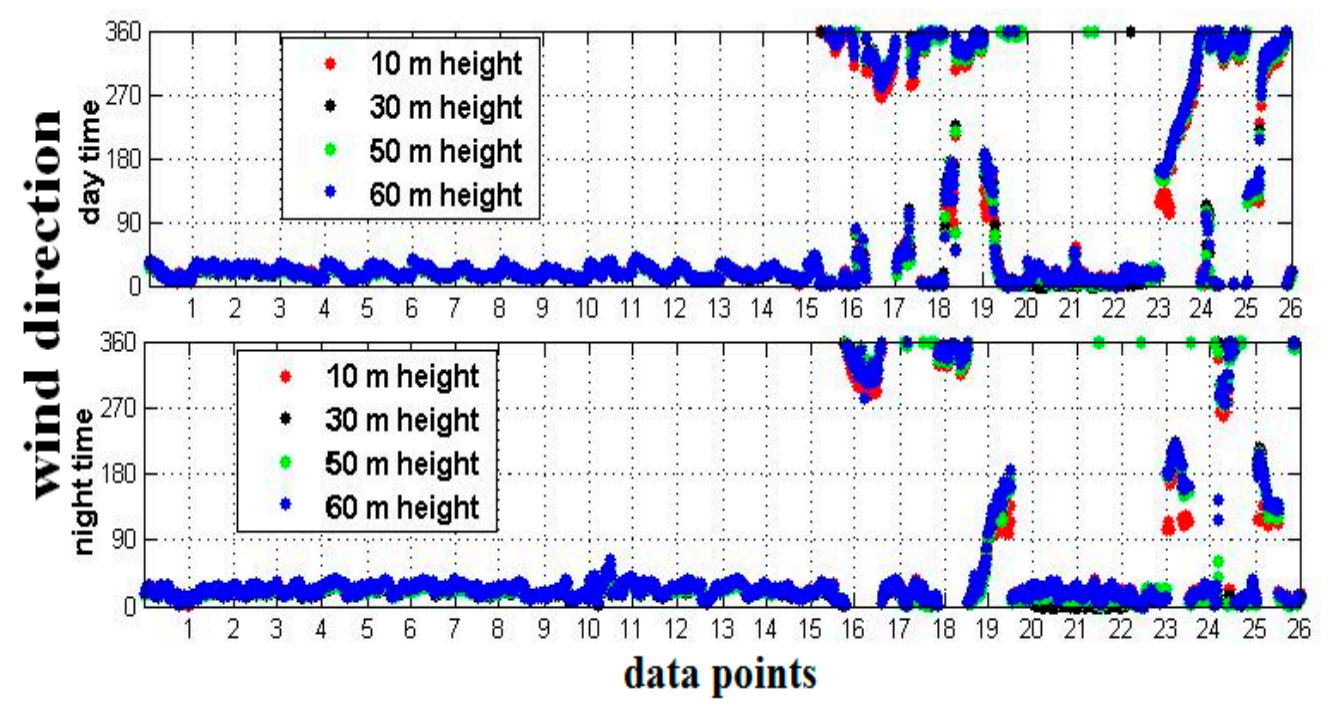

Figure 8. Day time and night time wind directions at Fuhai met mast.

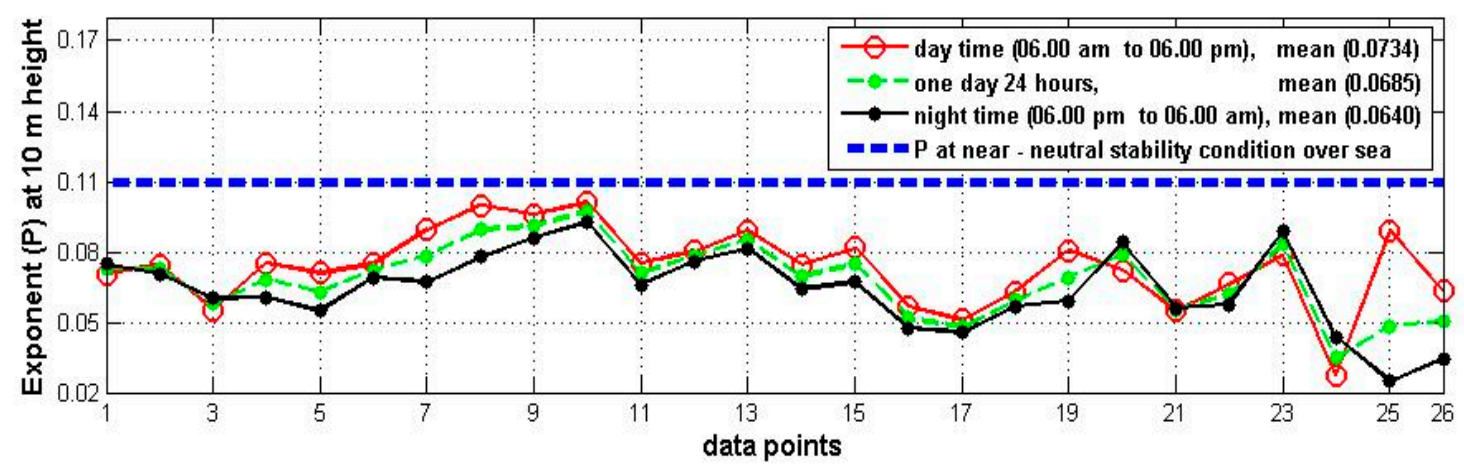

Figure 9. Power law exponent at Fuhai met mast at 10m height wind speed.

\section{Conclusions}

WAsP short period wind climate predictions are consistent with Lidar and at least three days wind data is recommended. The wind climate simulations accuracy depends on the quality of raw wind data. WRF model YSU (Yonsei University) scheme is not suitable for short-term forecasts. It is not suitable for offshore application but at unstable condition simulates well [6]. The $3.33 \mathrm{~km} \& 2 \mathrm{~km}$ grid lengths simulations are entirely different from each other because of its poor estimations at the stable conditions and overestimation at wind speed $15(\mathrm{~m} / \mathrm{s})$ [6]. The WRF model YSU (Yonsei University) scheme simulated wind data not recommended for the wind farm energy predictions in WAsP. Lukang 10 years mean wind data simulated wind speed $8.94(\mathrm{~m} / \mathrm{s}) \& 11.41(\mathrm{~m} / \mathrm{s})$ under purely neutral \& stable atmospheric condition at Fuhai met mast at $100 \mathrm{~m}$ height. Among three wind farm layouts $\left(0^{\circ}, 30^{\circ}, \& 60^{\circ}\right), 60^{\circ}$ wind farm layout predicted high efficiency at neutral and stable condition is $91.76 \%$ \& $92.44 \%$. TGC wind farm efficiency at neutral and stable condition is $90.58 \%$ \& $92.39 \%$. For TGC wind farm layout favorable wind direction is in the year $2004 \& 2005$ and year 2010 is 
unfavorable. At Fuhai met mast average of 26 data points' roughness length is lesser than $0.0002 \mathrm{~m}$ and only at typhoon period data points crossed $0.0002 \mathrm{~m}$. Power law exponent of one day average wind speed shown unstable atmospheric condition. Night time is more unstable condition than the day time.

\section{Acknowledge}

The authors gratefully acknowledge the support provided by the Ministry of Science and Technology, Taiwan, ROC through Grant No. MOST 105-3113-E-006-016 -CC2 and MOST 105-2221-E-006-135. Our sincere gratitude also goes to Taiwan Generations Corporation for its facility support throughout the measurements

\section{Author Contributions}

J.J. Miau and Pei-Chi Chang conceived and designed the experiments; Pei-Chi Chang and Meharkumar Barapati performed the experiments; J.J. Miau, Pei-Chi Chang and Meharkumar Barapati analyzed the data; Meharkumar Barapati wrote the article, Pei-Chi Chang and J.J. Miau update and revise the article.

\section{Conflicts of interest:}

The authors declare no conflict of interest

\section{Reference:}

1. Jan S, Wang J, Chern CS, Chao SY. Seasonal variation of the circulation in the Taiwan Strait. Journal of Marine Systems. 2002 Jul 1;35(3):249-68.

2. Fang HF. Wind energy potential assessment for the offshore areas of Taiwan west coast and Penghu Archipelago. Renewable Energy. 2014 Jul 31;67:237-41.

3. IEC T. 61400-14," Wind turbines-Part 14: Declaration of apparent sound power level and tonality values". International Technical Commission, Geneva. 2005.

4. Chang PC, Yang RY, Lai CM. Potential of offshore wind energy and extreme wind speed forecasting on the west coast of Taiwan. Energies. 2015 Feb 27;8(3):1685-700.

5. Taiwan generation corp. Fuhai offshore wind farm project's report on wave heights of Taiwan Strait, http://www.taiwangenerations.com/english/project.php?projectid=7 ; (accessed on 10 July 2016).

6. Krogsæter O, Reuder J. Validation of boundary layer parameterization schemes in the weather research and forecasting model under the aspect of offshore wind energy applications-Part I: Average wind speed and wind shear. Wind Energy. 2015 May 1;18(5):769-82.

7. Storm B, Dudhia J, Basu S, Swift A, Giammanco I. Evaluation of the weather research and forecasting model on forecasting low-level jets: Implications for wind energy. Wind Energy. 2009 Jan 1;12(1):8190.

8. Shimada S, Ohsawa T. Accuracy and characteristics of offshore wind speeds simulated by WRF. Sola. 2011;7:21-4.

9. Bilgili M, Yasar A, Simsek E. Offshore wind power development in Europe and its comparison with onshore counterpart. Renewable and Sustainable Energy Reviews. 2011 Feb 28;15(2):905-15.

10. Lynn PA. Onshore and offshore wind energy: an introduction. John Wiley \& Sons; 2011 Dec 12. 
11. Brower M. Wind resource assessment: a practical guide to developing a wind project. John Wiley \& Sons; 2012 Jun 19.

12. Samorani M. The wind farm layout optimization problem. InHandbook of Wind Power Systems 2013 (pp. 21-38). Springer Berlin Heidelberg.

13. Gaumond M, Réthoré PE, Ott S, Pena A, Bechmann A, Hansen KS. Evaluation of the wind direction uncertainty and its impact on wake modeling at the Horns Rev offshore wind farm. Wind Energy. 2014 Aug 1;17(8):1169-78.

14. Barthelmie RJ, Jensen LE. Evaluation of wind farm efficiency and wind turbine wakes at the Nysted offshore wind farm. Wind Energy. 2010 Sep 1;13(6):573-86.

15. Sørensen T, Thøgersen ML, Nielsen P, Jernesvej N. Adapting and calibration of existing wake models to meet the conditions inside offshore wind farms. EMD International A/S. Aalborg. 2008 Feb.

16. Hasager CB, Vincent P, Badger J, Badger M, Di Bella A, Peña A, Husson R, Volker PJ. Using satellite SAR to characterize the wind flow around offshore wind farms. Energies. 2015 Jun 5;8(6):5413-39.

17. Peña A, Hasager C, Husson R. Far wake wind field comparison between satellite retrievals and microscale model results. InEWEA Offshore 2015 Conference 2015.

18. Bergeron NE, Abrahams AD. Estimating shear velocity and roughness length from velocity profiles. Water Resources Research. 1992 Aug 1;28(8):2155-8.

19. Lange B, Larsen S, Højstrup J, Barthelmie R. Importance of thermal effects and sea surface roughness for offshore wind resource assessment. Journal of wind engineering and industrial aerodynamics. 2004 Sep 30;92(11):959-88.

20. Climatevo weather website. Daily weather reports of Changhua area, http://climatevo.com/2014-

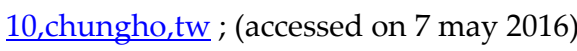

21. Wikipedia of Typhoon Vongfong (2014). Typhoon effects on Taiwan, https://en.wikipedia.org/wiki/Typhoon Vongfong_(2014); 2016 (accessed on 28 may).

22. Kuo NJ, Ho CR. ENSO effect on the sea surface wind and sea surface temperature in the Taiwan Strait. Geophysical Research Letters. 2004 Jul 1;31(13).

23. Wikipedia of Taiwan. Climatic conditions of Taiwan at different seasons, https://en.wikipedia.org/wiki/Taiwan ; (accessed on 28 may 2016).

24. Lin SF, Tang TY, Jan S, Chen CJ. Taiwan Strait current in winter. Continental Shelf Research. 2005 Jun 30;25(9):1023-42.

25. Wikipedia of Typhoon Koppu (2014). Typhoon effects on Taiwan, https://en.wikipedia.org/wiki/Typhoon_Koppu ; (accessed on 7 may 2016).

26. Hsu SA. Estimating overwater friction velocity and exponent of power-law wind profile from gust factor during storms. Journal of waterway, port, coastal, and ocean engineering. 2003 Jul;129(4):174-7.

27. Hsu SA, Meindl EA, Gilhousen DB. Determining the power-law wind-profile exponent under nearneutral stability conditions at sea. Journal of Applied Meteorology. 1994 Jun;33(6):757-65.

(C) 2016 by the authors; licensee Preprints, Basel, Switzerland. This article is an open access article distributed under the terms and conditions of the Creative Commons by Attribution (CC-BY) license (http://creativecommons.org/licenses/by/4.0/). 